\title{
BMJ Open Trends in self-poisoning and psychotropic drug use in people aged 5-19 years: a population-based retrospective cohort study in Australia
}

\author{
Rose Cairns, ${ }^{1,2}$ Emily A Karanges, ${ }^{3}$ Anselm Wong, ${ }^{4}$ Jared A Brown, ${ }^{1}$ Jeff Robinson, ${ }^{5}$ \\ Sallie-Anne Pearson, ${ }^{3}$ Andrew H Dawson, ${ }^{1,6}$ Nicholas A Buckley ${ }^{1,7}$
}

To cite: Cairns R, Karanges EA, Wong A, et al. Trends in selfpoisoning and psychotropic drug use in people aged 5-19 years: a populationbased retrospective cohort study in Australia. BMJ Open 2019;9:e026001. doi:10.1136/ bmjopen-2018-026001

- Prepublication history and additional material for this paper are available online. To view these files, please visit the journal online (http://dx.doi org/10.1136/bmjopen-2018026001).

Received 15 August 2018 Revised 2 November 2018 Accepted 12 December 2018

Check for updates

(C) Author(s) (or their employer(s)) 2019. Re-use permitted under CC BY-NC. No commercial re-use. See rights and permissions. Published by BMJ.

For numbered affiliations see end of article.

Correspondence to

Dr Rose Cairns;

rose.cairns@health.nsw.gov.au

\section{ABSTRACT}

Objectives To characterise trends in self-poisoning and psychotropic medicine use in young Australians.

Design Population-based retrospective cohort study.

Setting Calls taken by the New South Wales and Victorian Poisons Information Centres (2006-2016, accounting for $70 \%$ of Australian poisoning calls); medicine dispensings in the $10 \%$ sample of Australian Pharmaceutical Benefits Scheme data (July 2012 to June 2016).

Participants People aged 5-19 years.

Main outcome measures Yearly trends in intentional poisoning exposure calls, substances taken in intentional poisonings, a prevalence of psychotropic use (dispensing of antidepressants, antipsychotics, benzodiazepines and medicines for attention deficit hyperactivity disorder (ADHD)).

Results There were 33501 intentional poisonings in people aged $5-19$ years, with an increase of $8.39 \%$ per year $(95 \% \mathrm{Cl} 6.08 \%$ to $10.74 \%, \mathrm{p}<0.0001)$, with a $98 \%$ increase overall, 2006-2016. This effect was driven by increased poisonings in those born after 1997, suggesting a birth cohort effect. Females outnumbered males 3:1. Substances most commonly taken in self-poisonings were paracetamol, ibuprofen, fluoxetine, ethanol, quetiapine, paracetamol/opioid combinations, sertraline and escitalopram. Psychotropic dispensing also increased, with selective serotonin reuptake inhibitors (SSRIs) increasing 40\% and 35\% July 2012 to June 2016 in those aged 5-14 and 15-19, respectively. Fluoxetine was the most dispensed SSRI. Antipsychotics increased by $13 \%$ and $10 \%$, while ADHD medication dispensing increased by $16 \%$ and $10 \%$, in those aged $5-14$ and $15-19$, respectively. Conversely, dispensing of benzodiazepines to these age groups decreased by $4 \%$ and $5 \%$, respectively. Conclusions Our results signal a generation that is increasingly engaging in self-harm and is increasingly prescribed psychotropic medications. These findings indicate growing mental distress in this cohort. Since people who self-harm are at increased risk of suicide later in life, these results may foretell future increases in suicide rates in Australia.

\section{INTRODUCTION}

Rates of self-harm increase sharply during adolescence, especially in females. It is
Strengths and limitations of this study

- This study uses a large dataset $(70 \%$ of Australian poisons centre calls), over a long period (20062016), to comprehensively describe child and adolescent self-poisoning in Australia.

- Calls are coded by specialists in poisons information, and thus, coding of substances taken is of high quality and more sensitive than hospital coding.

- The Pharmaceutical Benefits Scheme 10\% sample is a nationwide dispensing dataset, allowing us to estimate psychotropic medicine use in this age group.

- Retrospective study design.

- Not all poisonings result in a call to a Poisons Information Centre, thus, our study does not capture all self-poisonings in this age group.

estimated that around $10 \%$ of adolescents have self-harmed at some point, with self-poisoning the most common form of hospitalised selfharm in children and adolescents. ${ }^{1}$ Self-poisoning has a low case fatality rate ${ }^{2}$ however, self-poisoning episodes are often predictive of mental health problems later in life. ${ }^{3}$ The risk of completed suicide in the year following self-poisoning is markedly increased relative to reference individuals and this increased risk persists over the following decade. ${ }^{3}$ Suicide is the third most common cause of death among adolescents worldwide. ${ }^{4}$ Evidence from the USA and UK suggests that rates of self-poisoning/self-harm in children and adolescents have increased at the beginning of this decade. ${ }^{5-7}$ Two recent Australian studies have shown increases in emergency department presentations for the child and adolescent selfharm in New South Wales (NSW), 2010-2014, ${ }^{8}$ and Victoria, 2008-2015. ${ }^{9}$

Like self-harm, use of psychotropics may act as a proxy measure for mental well-being. Internationally, rates of psychotropic medicine 
use in children and adolescents have been increasing. ${ }^{10-12}$ From 2009 to 2012, antidepressant, antipsychotic and attention deficit hyperactivity disorder (ADHD) medicine use increased by $25 \%, 31 \%$ and $24 \%$, respectively, in Australians under the age of $25 .{ }^{13}$ Psychotropic medicines are commonly used in deliberate self-poisoning, ${ }^{1415}$ and there is some evidence that use of certain psychotropic medicines in people under 25 is associated with increased suicidality. ${ }^{16}$

There are limited data on more recent time trends in self-poisoning and psychotropic medicine use in young Australians. This study aims to characterise Australian trends in self-poisoning and psychotropic dispensing in young people. Specifically, we aim to: (1) evaluate trends in deliberate self-poisoning in Australians aged 5-19 years, 2006-2016, (2) identify substances most commonly used in self-poisoning by children and adolescents and (3) analyse trends in psychotropic medicine dispensing to children and adolescents, 2012-2016.

\section{METHODS \\ Design}

This is a retrospective cohort study of self-poisonings and psychotropic dispensings in Australians aged 5-19 years. Poisons Information Centre (PIC) data provide up to date and detailed information on self-poisoning behaviours. Australia has four PICs, together providing nationwide poisoning advice to healthcare professionals and members of the public. We used data from the NSWPIC and Victorian PIC (VPIC), which together take approximately $70 \%$ of the nation's 200000 yearly poisoning calls. For the purposes of this study, a 'child' is defined as someone aged 5-14 years, and an 'adolescent' is between the ages of 15 and 19 years (as PICs use these categories when coding calls).

We also used psychotropic dispensing data, as a separate proxy measure for mental well-being. For the purposes of this study, psychotropic pharmaceuticals included antidepressants, benzodiazepines, antipsychotics, psychostimulants and clonidine. Australia has a publicly funded universal healthcare system, with subsidised medicines available to citizens and permanent residents under the Pharmaceutical Benefits Scheme (PBS). We used PBS dispensing data from a random $10 \%$ sample of PBS-eligible Australians. This nationwide data source has been described in detail previously. ${ }^{18}$ This is a standard dataset provided by the Australian Government Department of Human Services and is the gold standard for pharmacoepidemiology research in Australia.

\section{Data sources}

The NSWPIC and VPIC databases

The NSWPIC and VPIC databases were searched from 2006 to 2016 for calls where the exposure type was 'intentional' (this includes deliberate self-poisoning, recreational use and intentional misuse). Calls were included if the patient's age category at the time of poisoning was coded as 'Child' or 'Adolescent'. Exact age was recorded in over $97 \%$ of cases (other calls were coded as either child or adolescent without a precise age specified).

PIC data were recoded by RC (poisons information specialist) to harmonise substance codes between the different centres. Substances were divided into broad categories for trend analysis: non-narcotic analgesics (paracetamol, aspirin, non-steroidal anti-inflammatory drugs), psychotropics (antidepressants, antipsychotics, anxiolytics/sedatives, psychostimulants), opioids (non-illicit), other prescription pharmaceuticals, other over-thecounter pharmaceuticals, gases (eg, carbon monoxide) and other non-pharmaceutical substances (including household products, chemicals, pesticides, plants).

We also categorised medicines taken in overdose into three categories based on the Australian Medicines Handbook Children's Dosing Companion (AMHCDC, July 2017 online version): approved in children, 'off-label, accepted' (not in manufacturer's product information (PI) but in the AMHCDC), and 'off-label, not accepted' (not in the PI or AMHCDC).

Since PICs often receive multiple calls about the one exposure (eg, family member, then triage nurse and doctor), these subsequent calls ('recalls') were excluded from the analysis. Note that these data relate to self-poisoning events, one individual may have repeated self-poisonings, and thus may be included several times in this dataset.

Intentional exposure counts (all ages) from NSWPIC and VPIC were also extracted to allow comparison to overall trends.

\section{PBS 10\% sample}

We extracted psychotropic dispensings in people aged 5-19 years. Note that year of birth is perturbed 180 days so this provides only an estimate of age.

Prior to 2012, the PBS $10 \%$ sample only captured dispensings where the government paid a contribution. For cheaper medicines, some beneficiaries pay the full cost of the medicine (defined as 'under copayment'), and these dispensings were not captured prior to 2012. ${ }^{18}$ Due to these data capture changes, we extracted dispensings from July 2012 to June 2016 for in-depth analysis. Longer term data (2006-2015, excluding under copayment dispensings) were extracted for the same medicines to allow comparison to longer term trends.

\section{Data analysis}

We analysed time trends in poisonings using negative binomial regression with a log link function. We analysed self-poisoning by individual age at the time of the episode. We also created the year of birth cohorts by estimating a birth year from age at the time of call (online supplementary table 1). Poisonings per birth year cohort per year were plotted graphically. ${ }^{19}$

For our primary analysis of PBS data (July 2012 to June 2016), we estimated the monthly prevalence of psychotropic use (by class, subclass and individual medicine) for individuals aged 5-14 years, 15-19 years and both groups combined (5-19 years). A prevalence was estimated from 


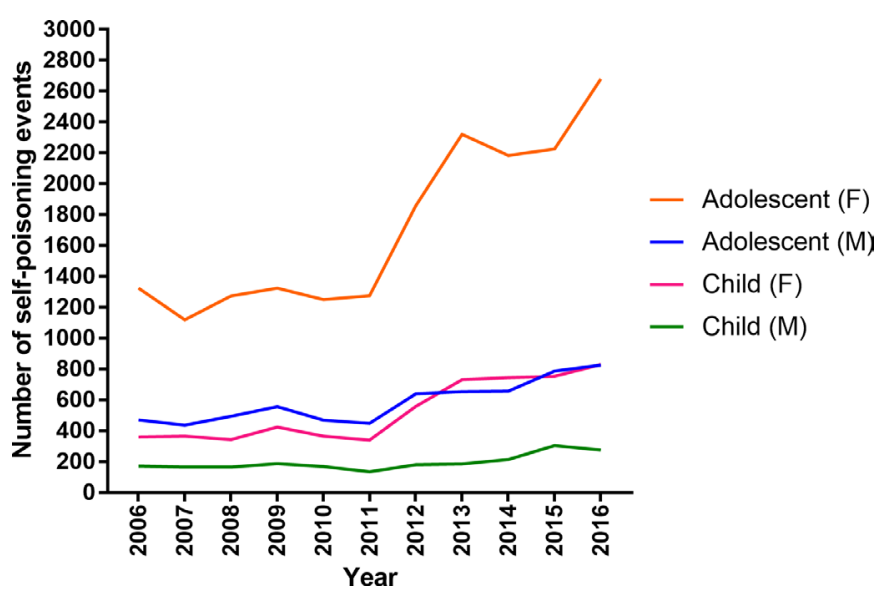

Figure 1 Trends in intentional poisonings in children and adolescents reported to the NSWPIC and VPIC, 2006-2016. NSWPIC, New South Wales Poisons Information Centre; VPIC, Victorian Poisons Information Centre.

the number of individuals with at least one dispensing of a psychotropic class, subclass or specific medicine in a given month. We reported the prevalence as the number of users per 10000 population, using population estimates obtained from the Australian Bureau of Statistics (using national population figures, as the PBS $10 \%$ sample is a nationwide database). We also used linear regression analysis to calculate slope changes and 95\% CIs. Data were not shown if there were less than 30 persons in the $10 \%$ sample dispensed that subclass or medicine in at least 1 month examined. For graphical presentations of monthly data, 12-month rolling averages were used to smooth seasonality in the PBS data (due to medicine stockpiling at the end of each year).$^{18}$ For our secondary analysis (2006-2015), we calculated yearly prevalence (ie, the number of individuals with at least one dispensing of a psychotropic class, subclass or specific psychotropic in a given year/10 000 population).

Data analysis and presentation was performed with GraphPad Prism V.7.00 (GraphPad Software, La Jolla, California, USA), Tableau Desktop V.9.3 (Tableau Software, Seattle, Washington, USA) and SAS V.9.4 (SAS).

\section{Patient and public involvement}

This was a retrospective review of routinely collected data. Patients and the public were not involved in the design or the recruitment of the study.

\section{Data access approvals}

Access to the PBS 10\% sample was approved by the Australian Department of Human Services External Request Evaluation Committee.

\section{RESULTS}

\section{Intentional poisonings}

In the 11-year study period, the NSWPIC and VPIC databases recorded 8053 intentional poisonings in individuals aged 5-14 years and 25448 intentional poisonings in those aged 15-19 years (total 33501 poisonings in people

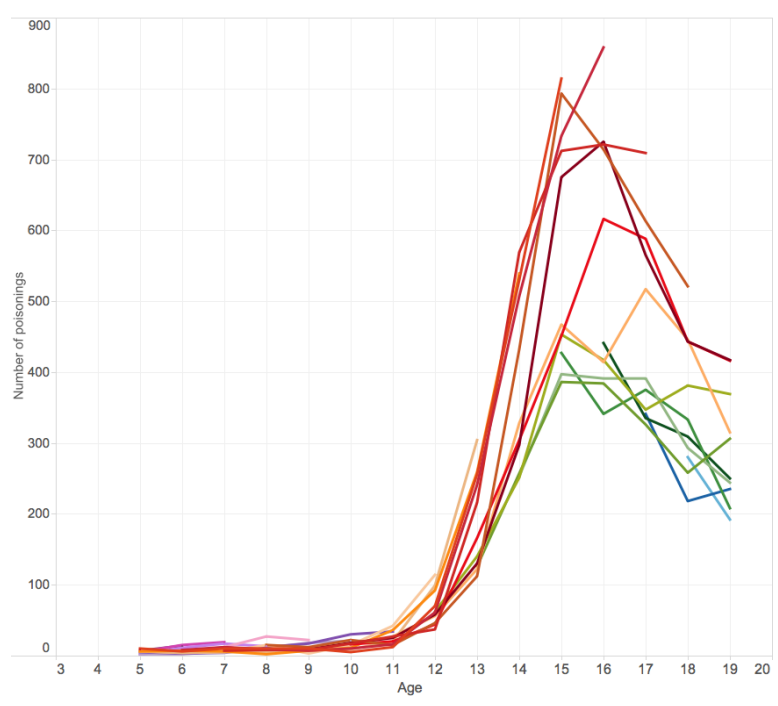

Figure 2 Number of intentional poisonings by birth year cohort at ages 5-19 years, 2006-2016.

aged 5-19 years). Numbers of self-poisonings in those aged 5-19 years increased by $8.39 \%$ per year $(95 \%$ CI $6.08 \%$ to $10.74 \%, \mathrm{p}<0.0001)$, with an overall increase of 98\%, 2006-2016 (figure 1). Self-poisonings in children increased by $9.00 \%$ per year (95\% CI $6.26 \%$ to $11.81 \%$, $\mathrm{p}<0.0001$ ), overall 107\%, 2006-2016. Adolescent self-poisonings increased by $8.21 \%$ per year, (95\% CI $5.96 \%$ to $10.5 \%, \mathrm{p}<0.0001$ ) or $96 \%$ over the study period. By comparison, we observed an overall increase of $15 \%$ in self-poisoning in persons aged 20 years and over, 20062016. In children and adolescents, self-poisonings for females outnumbered those for males by 3-1 (figure 1). Self-poisoning in females increased by $108 \%$ in total, $9.21 \%$ per year, (95\% CI $6.63 \%$ to $11.86 \%, \mathrm{p}<0.0001$ ), while in males increased by $72 \%$ in total, $6.03 \%$ per year (95\% CI $3.96 \%$ to $8.14 \%, \mathrm{p}<0.0001)$.

Self-poisoning increased dramatically and is consistently higher in those born after 1997 (figure 2), indicating a birth cohort effect. Overall, substances most commonly used in self-poisoning episodes included analgesics (including those available without a prescription) and psychotropics (table 1); many exposures were to medicines where use in children/adolescents is 'off-label'. Time trends in exposures to agents broken down by broad substance classes (online supplementary figure 1) show large increases in poisonings with psychotropics and non-narcotic analgesics.

\section{Psychotropic dispensing}

We observed increases in the number of individuals aged 5-19 dispensed specific psychotropic medicines. From July 2012 to June 2016, selective serotonin reuptake inhibitor (SSRI) dispensing increased $40 \%$ and $35 \%$ in those aged 5-14 and 15-19, respectively (table 2, figure 3). Males received $\sim 60 \%$ of antidepressants in the age group of 5-14years. Conversely, in those aged 15-19, females received $65 \%$ of antidepressant dispensings (table 2, figure 3). Fluoxetine was the most dispensed 
Table 1 The most common substances ingested in child and adolescent self-poisoning events to NSWPIC and VPIC, 2006-2016 $(n=33501)$

\begin{tabular}{|c|c|c|c|}
\hline & 5-14years & 15-19years & $\begin{array}{l}\text { Grand } \\
\text { total }\end{array}$ \\
\hline Paracetamo/* & 1901 & 6028 & 7929 \\
\hline Ibuprofen ${ }^{\star}$ & 785 & 2782 & 3567 \\
\hline Fluoxetine & 428 & 1663 & 2091 \\
\hline Ethanol & 207 & 1786 & 1993 \\
\hline Quetiapine & 313 & 1534 & 1847 \\
\hline Paracetamol/opioid* & 266 & 1257 & 1523 \\
\hline Sertraline & 166 & 1315 & 1481 \\
\hline Escitalopram & 91 & 762 & 853 \\
\hline $\begin{array}{l}\text { Cough/cold preparations: paracetamol } \\
\text { based* }^{*}\end{array}$ & 129 & 704 & 833 \\
\hline Diazepam & 113 & 718 & 831 \\
\hline Methylphenidate & 317 & 500 & 817 \\
\hline Promethazine ${ }^{*}$ & 168 & 549 & 717 \\
\hline Caffeine $^{\star}$ & 200 & 463 & 663 \\
\hline Venlafaxine & 61 & 476 & 537 \\
\hline Aspirin/acetylsalicylic acid ${ }^{\star}$ & 112 & 425 & 537 \\
\hline Valproic acid & 114 & 398 & 512 \\
\hline Clonidine & 221 & 259 & 480 \\
\hline Olanzapine & 64 & 408 & 472 \\
\hline Temazepam & 63 & 405 & 468 \\
\hline Ibuprofen, combinations* & 82 & 365 & 447 \\
\hline Bleach $^{*}$ & 138 & 304 & 442 \\
\hline Fluvoxamine & 86 & 349 & 435 \\
\hline Risperidone & 146 & 286 & 432 \\
\hline Mirtazapine & 60 & 343 & 403 \\
\hline Citalopram & 62 & 326 & 388 \\
\hline Miscellaneous medicine $\%$ & 88 & 276 & 364 \\
\hline Oxycodone & 47 & 306 & 353 \\
\hline Herbal preparations ${ }^{\star}$ & 82 & 265 & 347 \\
\hline Desvenlafaxine & 26 & 314 & 340 \\
\hline Ecstasy (MDMA) & 20 & 310 & 330 \\
\hline Amitriptyline & 66 & 253 & 319 \\
\hline Marijuana & 47 & 264 & 311 \\
\hline Doxylamine* & 52 & 253 & 305 \\
\hline Amphetamines (illicit) & 23 & 248 & 271 \\
\hline Alprazolam & 44 & 221 & 265 \\
\hline Diclofenac* & 59 & 204 & 263 \\
\hline
\end{tabular}

Shaded rows: prescription medicine not approved for children in manufacturer product information.

Bold: not approved for children in manufacturer product information and not in Australian Medicines Handbook Children's Dosing Companion (see the Methods section for further details).

Italics*: available over the counter/unscheduled

$\%$ : includes cases where the medication was unknown, or purchased overseas/over the internet (not marketed in Australia).

MDMA, methylenedioxymethamphetamine; NSWPIC, New South Wales

Poisons Information Centre; VPIC, Victorian Poisons Information Centre.

SSRI across both genders and age groups (increasing $54 \%$ and $44 \%$ in those aged 5-14 and 15-19, respectively). Escitalopram, fluvoxamine and sertraline were also commonly used in the older age group. Use of other antidepressant classes was lower, although venlafaxine and mirtazapine increased $27 \%$ and $34 \%$, respectively, in those aged $15-19$ (table 2 ). Males received $\sim 80 \%$ of antipsychotics in the age group of 5-14years, decreasing to $\sim 60 \%$ in the age group of $15-19$ years (table 3 ). Trends in antipsychotic dispensing in people aged 5-19 show that risperidone and quetiapine are the most used, with a $19 \%$ increase in risperidone dispensing (table 3). In people aged 5-19 years, $80 \%$ of ADHD medication dispensing was to males. ADHD medicine dispensing has increased $14 \%$ in people aged 5-19, with clonidine and methylphenidate dispensing increasing $26 \%$ and $17 \%$, respectively. Conversely, dispensing of benzodiazepines to this age group is relatively uncommon and has decreased by $6 \%$. Females were dispensed $\sim 60 \%$ of benzodiazepines. Longer term trends (2006-2015), without under copayment data are displayed in online supplementary figures $2-4$, indicating that these recent changes are largely an extension of longer term trends.

\section{DISCUSSION}

There was a substantial increase in child and adolescent self-poisonings in the poisons centre databases over the 11-year study period. There appears to be a cohort effect, with those born after 1997 largely accounting for the increase in self-poisonings in the PIC dataset. Young females were over-represented in self-poisoning events, and the rate of increase was higher in females. The poisons most commonly used reflect the substances widely available in the community (such as household products and over-the-counter medicines) and substances commonly prescribed to children/adolescents. Psychotropic prescribing in children and adolescents has increased. In particular, SSRI prescribing has increased substantially. There is substantial overlap between the most dispensed psychotropics and medicines most commonly used in self-poisoning episodes.

\section{Strengths and limitations}

These results should be viewed in light of the strengths and limitations of this study. As discussed above, there have been recent reports of increases in adolescent selfharm presentations to emergency departments in NSW and Victoria (Australia's two most populous states). Hospital presentation data have limited sensitivity, and many self-poisonings may be coded as the presenting symptom. ${ }^{20}$ Even when self-poisonings are identified, the agents involved cannot be well classified with clinical coding systems (such as The International Statistical Classification of Diseases and Related Health Problems, tenth revision (ICD-10) and Systematized Nomenclature of Medicine - Clinical Terms (SNOMED-CT)), and are generally coded under broad pharmacological groups. PIC data provide up-to-date data on self-poisonings in Australia with detailed capture of substances involved. Substances are coded in real time by specialists in poisons information (pharmacists and pharmacologists 
Table 2 Time trends and gender distribution antidepressant dispensing prevalence (persons/10 000 population/month) in Australians aged $5-19$ years

\begin{tabular}{|c|c|c|c|c|c|c|}
\hline & $\begin{array}{l}\% \text { Female } \\
\text { July } 12 \text { to June } \\
13\end{array}$ & $\begin{array}{l}\% \text { Female } \\
\text { July } 15 \text { to June } \\
16\end{array}$ & $\begin{array}{l}\text { Monthly ave. } \\
\text { July } 12 \text { to June } \\
13\end{array}$ & $\begin{array}{l}\text { Monthly ave. } \\
\text { July } 15 \text { to June } \\
16\end{array}$ & $\begin{array}{l}\text { Rate of increase per month } \\
(95 \% \mathrm{Cl})^{*}\end{array}$ & $\begin{array}{l}\% \text { Change, } 2012 / 2013 \text { to } \\
2015 / 2016\end{array}$ \\
\hline \multicolumn{7}{|l|}{$5-14$ years } \\
\hline SSRIS & 38 & 41 & 23.15 & 32.41 & 0.23 (0.16 to 0.3$)$ & 40 \\
\hline Citalopram & $\dagger$ & $\dagger$ & $\dagger$ & $\dagger$ & & \\
\hline Fluvoxamine & 36 & 43 & 3.54 & 4.82 & $0.029(0.018$ to 0.041$)$ & 36 \\
\hline Paroxetine & $\dagger$ & $\dagger$ & $\dagger$ & $\dagger$ & & \\
\hline Sertraline & 38 & 43 & 5.11 & 6.07 & $0.02(0.0038$ to 0.035$)$ & 19 \\
\hline SNRI & $\dagger$ & $\dagger$ & $\dagger$ & $\dagger$ & & \\
\hline NaSSA & $\dagger$ & $\dagger$ & $\dagger$ & $\dagger$ & & \\
\hline SSRI & 65 & 65 & 147.63 & 198.60 & $1.3(1$ to 1.5$)$ & 35 \\
\hline Citalopram & 67 & 66 & 9.69 & 8.85 & $-0.033(-0.057$ to -0.0093$)$ & -9 \\
\hline Escitalopram & 70 & 68 & 30.49 & 39.62 & 0.21 (0.12 to 0.29$)$ & 30 \\
\hline Fluoxetine & 63 & 63 & 55.68 & 80.35 & 0.66 (0.58 to 0.73$)$ & 44 \\
\hline Fluvoxamine & 56 & 57 & 11.09 & 15.89 & 0.12 (0.097 to 0.14$)$ & 43 \\
\hline Paroxetine & 62 & 66 & 3.69 & 5.59 & 0.049 (0.037 to 0.06$)$ & 51 \\
\hline Sertraline & 66 & 66 & 37.79 & 49.83 & 0.31 (0.24 to 0.38$)$ & 32 \\
\hline SNRI & 70 & 70 & 29.31 & 33.42 & $0.071(-0.02$ to 0.16$)$ & 14 \\
\hline Desvenlafaxine & 70 & 70 & 14.39 & 16.13 & $0.027(-0.018$ to 0.072$)$ & 12 \\
\hline SSRI & 59 & 59 & 65.54 & 87.90 & 0.56 (0.43 to 0.69$)$ & 34 \\
\hline Citalopram & 65 & 64 & 3.80 & 3.35 & $-0.016(-0.026$ to -0.0067$)$ & -12 \\
\hline Escitalopram & 69 & 66 & 11.26 & 14.52 & 0.073 (0.042 to 0.1$)$ & 29 \\
\hline Fluoxetine & 55 & 55 & 27.10 & 39.50 & 0.33 (0.28 to 0.37$)$ & 46 \\
\hline Fluvoxamine & 48 & 52 & 6.11 & 8.51 & 0.057 (0.044 to 0.071$)$ & 39 \\
\hline Paroxetine & 61 & 65 & 1.41 & 1.95 & 0.014 (0.0092 to 0.018$)$ & 38 \\
\hline Sertraline & 60 & 62 & 16.24 & 20.68 & $0.11(0.077$ to 0.14$)$ & 27 \\
\hline SNRI & 69 & 69 & 10.57 & 11.84 & $0.02(-0.013$ to 0.053$)$ & 12 \\
\hline Desvenlafaxine & 69 & 69 & 5.08 & 5.69 & $0.0091(-0.0074$ to 0.026$)$ & 12 \\
\hline Duloxetine & 66 & 70 & 2.27 & 2.26 & $-0.0026(-0.01$ to 0.0053$)$ & 0 \\
\hline Venlafaxine & 70 & 68 & 3.21 & 3.89 & 0.014 (0.0037 to 0.024$)$ & 21 \\
\hline NaSSA & 56 & 52 & 3.14 & 4.08 & 0.023 (0.013 to 0.033 ) & 30 \\
\hline Mirtazapine & 51 & 53 & 3.11 & 4.07 & 0.023 (0.013 to 0.033$)$ & 31 \\
\hline TCA & 49 & 55 & 6.57 & 6.57 & $-0.0066(-0.018$ to 0.0051$)$ & 0 \\
\hline
\end{tabular}

Bolded $\%$ change figures indicate significant changes (judged by a $95 \% \mathrm{Cl}$ that does not cross zero).

*Based on regression line to account for monthly fluctuation.

tData were not shown in medicines/classes where there were $<30$ persons in $10 \%$ sample on that class in at least 1 month examined.

NaSSA, noradrenergic and specific serotonergic antidepressant; SNRI, serotonin-norepinephrine reuptake inhibitor; SSRI, selective serotonin reuptake inhibitor;

TCA, tricyclic antidepressant. 

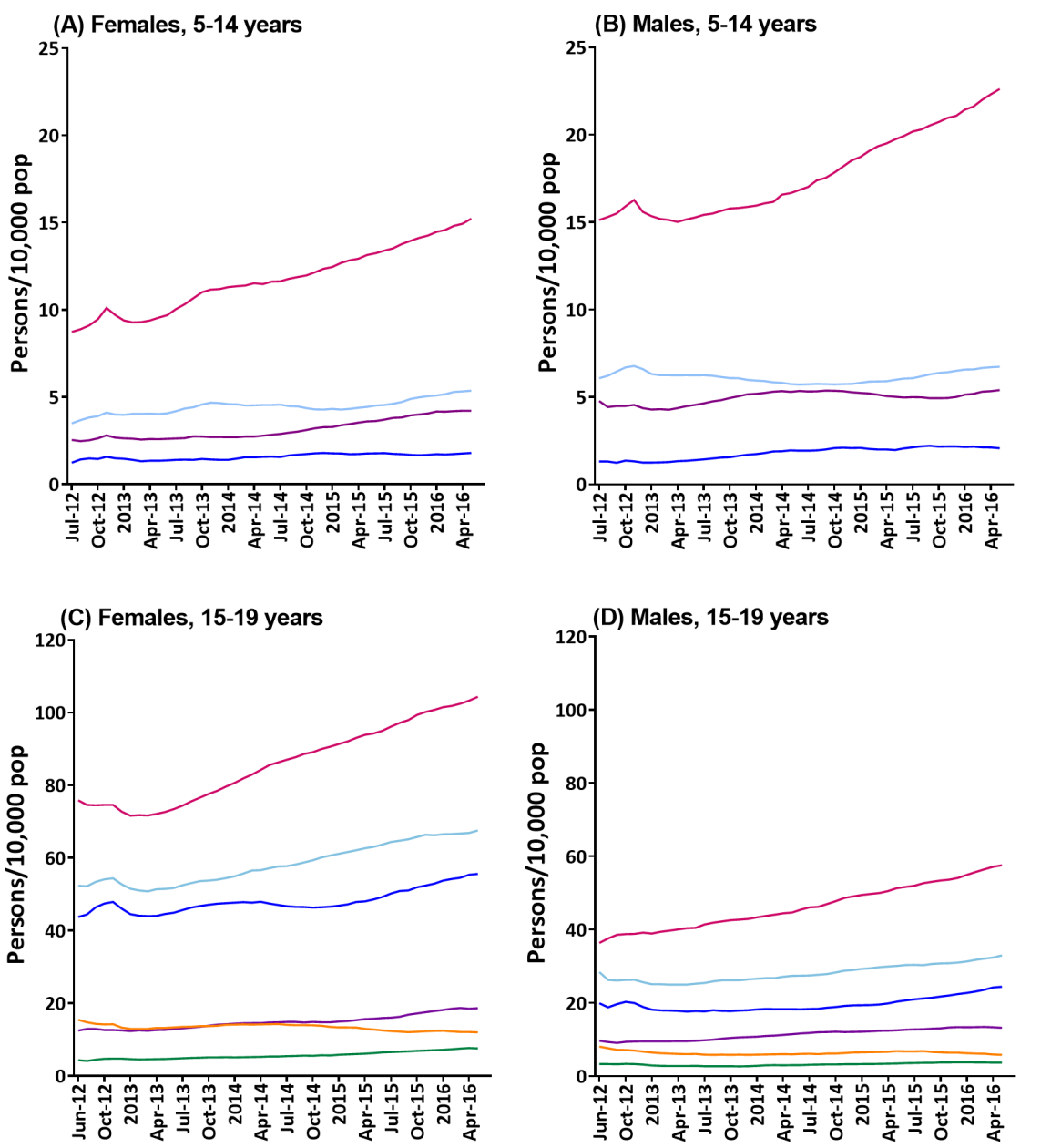

with postgraduate toxicology training) to a high standard. Capture of substances taken in overdose is much more detailed than routinely collected hospital presentation/admission data. Coding of exposure intent has been stable with time, with a categorisation of exposure intent (accidental, intentional) collected reliably since the early 1980s. Each call is reviewed within 12 hours by a colleague to further enhance accuracy. In addition, the increases observed in this study are on the background of decreasing overall calls to PICs, ${ }^{21}$ and thus could not be explained by increased service utilisation. There have been no changes in referral practices/PIC utilisation that could explain a surge in calls.

Another strength of this study is its capture of over a decade's worth of data from two of Australia's poisons centres, amounting to $70 \%$ of the nation's poisoning calls. This includes almost complete capture of poisons calls for the South East of Australia, plus some calls from the rest of the nation (due to the on-call structure shared by Australian PICs). NSWPIC and VPIC receive calls from members of the public and healthcare professionals across Australia and thus may provide better estimates of trends than studies conducted out of single hospitals.
However, this is not a complete capture of all child/ adolescent poisonings as calls to the PIC are voluntary, some hospitals may not call a PIC when a poisoning case presents, particularly those with local toxicology services or those staffed by experienced emergency physicians. Thus, this represents a conservative estimate of actual incidences of self-poisoning.

PBS data enable analysis of trends in the medicine dispensing on a nationwide scale but does not capture private scripts. However, it is estimated that private scripts account for less than $10 \%$ of dispensings in Australia. ${ }^{22}$ Due to PBS data capture changes, our primary analysis was on dispensings from 2012 onwards.

\section{Comparison with other studies}

This study signals a concerning increase in child/adolescent self-poisoning in Australia. Similar findings have been reported elsewhere in the world ${ }^{5-7} 23$ indicating that this may be a global trend. A 2015 global burden of disease study ranked the top 25 causes of death worldwide in children. Globally, in children 10-14 years, self-harm was ranked 13th and 12th in girls and boys, respectively. A similar picture is seen globally in adolescents aged 15-19 
Table 3 Time trends and gender distribution in antipsychotic, benzodiazepine and ADHD medication dispensing prevalence (persons/10 000 population/month) in Australians aged 5-19years

\begin{tabular}{|c|c|c|c|c|c|c|}
\hline & $\begin{array}{l}\% \text { Female, July } \\
12 \text { to June } 13\end{array}$ & $\begin{array}{l}\% \text { Female, July } 15 \\
\text { to June } 16\end{array}$ & $\begin{array}{l}\text { Monthly ave. July } 12 \\
\text { to June } 13\end{array}$ & $\begin{array}{l}\text { Monthly ave. July } 15 \\
\text { to June } 16\end{array}$ & $\begin{array}{l}\text { Rate of increase per month } \\
(95 \% \mathrm{Cl})^{\star}\end{array}$ & $\begin{array}{l}\text { \% Change, } 2012 / 2013 \text { to } \\
2015 / 2016\end{array}$ \\
\hline \multicolumn{7}{|l|}{$5-14$ years } \\
\hline Antipsychotics & 20 & 19 & 13.97 & 15.82 & $0.041(0.016$ to 0.067$)$ & 13 \\
\hline Typical & $\dagger$ & $\dagger$ & $\dagger$ & $\dagger$ & & \\
\hline Atypical & 20 & 19 & 13.38 & 15.31 & 0.044 (0.02 to 0.068$)$ & 14 \\
\hline Risperidone & 17 & 17 & 11.86 & 13.85 & 0.048 (0.029 to 0.067$)$ & 17 \\
\hline Olanzapine & $\dagger$ & $\dagger$ & $\dagger$ & $\dagger$ & & \\
\hline Quetiapine & $\dagger$ & $\dagger$ & $\dagger$ & $\dagger$ & & \\
\hline Aripiprazole & $\dagger$ & $\dagger$ & $\dagger$ & $\dagger$ & & \\
\hline Benzodiazepines & 54 & 46 & 1.72 & 1.65 & $-0.0041(-0.01$ to 0.0021$)$ & -4 \\
\hline Diazepam & $\dagger$ & $\dagger$ & $\dagger$ & $\dagger$ & & \\
\hline Temazepam & $\dagger$ & $\dagger$ & $\dagger$ & $\dagger$ & & \\
\hline ADHD medications & 18 & 20 & 106.59 & 123.13 & 0.39 (0.23 to 0.55$)$ & 16 \\
\hline Atomoxetine & 21 & 20 & 6.01 & 5.86 & $-0.0084(-0.02$ to 0.0038$)$ & -2 \\
\hline Clonidine & 22 & 24 & 12.99 & 16.58 & 0.091 (0.071 to 0.11$)$ & 28 \\
\hline Dexamfetamine & 15 & 18 & 7.87 & 7.41 & $-0.016(-0.027$ to -0.0044$)$ & -6 \\
\hline Methylphenidate & 18 & 19 & 88.1 & 103.04 & $0.36(0.21$ to 0.5$)$ & 17 \\
\hline \multicolumn{7}{|l|}{ 15-19years } \\
\hline Antipsychotics & 39 & 40 & 30.88 & 34.01 & $0.056(0.0063$ to 0.11$)$ & 10 \\
\hline Typical & $\dagger$ & $\dagger$ & $\dagger$ & t & & \\
\hline Atypical & 39 & 40 & 29.31 & 32.52 & 0.06 (0.012 to 0.11$)$ & 11 \\
\hline Risperidone & 19 & 25 & 11.27 & 13.77 & 0.073 (0.057 to 0.089$)$ & 22 \\
\hline Olanzapine & 35 & 45 & 5.15 & 4.74 & $-0.017(-0.033$ to -0.00035$)$ & -8 \\
\hline Quetiapine & 63 & 61 & 10.23 & 9.70 & $-0.033(-0.064$ to -0.0021$)$ & -5 \\
\hline Aripiprazole & $\dagger$ & $\dagger$ & $\dagger$ & $\dagger$ & & \\
\hline Benzodiazepines & 60 & 60 & 15.24 & 14.42 & $-0.036(-0.082$ to 0.011$)$ & -5 \\
\hline Diazepam & 57 & 56 & 7.58 & 8.21 & $0.012(-0.016$ to 0.04$)$ & 8 \\
\hline Temazepam & 61 & 64 & 5.49 & 4.43 & $-0.033(-0.052$ to -0.013$)$ & -19 \\
\hline ADHD medications & 22 & 23 & 70.79 & 77.52 & 0.22 (0.11 to 0.33$)$ & 10 \\
\hline Atomoxetine & 16 & 28 & 4.34 & 4.24 & $-0.0016(-0.012$ to 0.0085$)$ & -2 \\
\hline Clonidine & 22 & 25 & 7.96 & 9.46 & 0.046 (0.027 to 0.065$)$ & 19 \\
\hline Dexamfetamine & 23 & 23 & 8.88 & 6.32 & $-0.067(-0.082$ to -0.052$)$ & -29 \\
\hline Methylphenidate & 21 & 22 & 53.59 & 62.32 & 0.27 (0.17 to 0.37$)$ & 16 \\
\hline \multicolumn{7}{|l|}{$5-19$ years } \\
\hline Antipsychotics & 30 & 30 & 19.73 & 21.89 & $0.043(0.011$ to 0.075$)$ & 11 \\
\hline Typical & 30 & 32 & 1.01 & 0.93 & $-0.0032(-0.0061$ to -0.00031$)$ & -8 \\
\hline Atypical & 30 & 30 & 18.81 & 21.06 & $0.046(0.015$ to 0.077$)$ & 12 \\
\hline Risperidone & 18 & 19 & 11.66 & 13.82 & $0.056(0.043$ to 0.07$)$ & 19 \\
\hline Olanzapine & 35 & 46 & 1.95 & 1.73 & $-0.0082(-0.014$ to -0.002$)$ & -11 \\
\hline Quetiapine & 61 & 60 & 4.02 & 3.68 & $-0.017(-0.029$ to -0.0046$)$ & -8 \\
\hline Aripiprazole & 33 & 37 & 1.06 & 1.54 & 0.013 (0.01 to 0.016$)$ & 45 \\
\hline Benzodiazepines & 59 & 57 & 6.33 & 5.92 & $-0.017(-0.036$ to 0.0013$)$ & -6 \\
\hline Diazepam & 58 & 54 & 3.18 & 3.37 & $0.0023(-0.009$ to 0.013$)$ & 6 \\
\hline Temazepam & 59 & 63 & 2.01 & 1.60 & $-0.013(-0.02$ to -0.0056$)$ & -20 \\
\hline ADHD medications & 19 & 21 & 94.40 & 107.90 & $0.34(0.23$ to 0.45$)$ & 14 \\
\hline Atomoxetine & 20 & 22 & 5.44 & 5.32 & $-0.0058(-0.015$ to 0.003$)$ & -2 \\
\hline Clonidine & 22 & 24 & 11.28 & 14.21 & 0.077 (0.062 to 0.092$)$ & 26 \\
\hline Dexamfetamine & 18 & 20 & 8.21 & 7.05 & $-0.033(-0.044$ to -0.022$)$ & -14 \\
\hline Methylphenidate & 19 & 20 & 76.35 & 89.44 & $0.34(0.23$ to 0.44$)$ & 17 \\
\hline
\end{tabular}

Bolded \% change figures indicate significant changes (judged by a $95 \% \mathrm{Cl}$ that does not cross zero).

*Based on regression line to account for monthly fluctuation.

†Data were not shown in medicines/classes where there were $<30$ persons in $10 \%$ sample on that class in at least 1 month examined.

ADHD, attention deficit hyperactivity disorder. 
years, where self-harm is ranked second and third in females and males, respectively. Self-harm was not in the top 25 causes of death in children aged 5-9 years. ${ }^{24}$ Thus, self-harm is a substantial contributor to disease burden in children and adolescents worldwide. Any increase on this high base will have substantial overall effects on public health.

We have demonstrated large increases in certain psychotropic dispensings in those aged 5-19 years, particularly in antidepressants and antipsychotics. Unsurprisingly, psychotropics were commonly taken in overdose by this age group. Karanges et al recently described trends in psychotropic medicine use in Australians, 2009-2012. Dispensings of antidepressants and antipsychotics in children 10-14 years of age increased at a faster rate than in any other age group (35.5\% and $49.1 \%$, respectively). ${ }^{13}$ This increased prescribing is not a uniquely Australian trend, with increases in antipsychotic use also documented in the USA ${ }^{10}$ and the UK. ${ }^{12}$ Use of antidepressants in children has remained stable in the USA, however, is increasing in the UK. ${ }^{11}$ In Canada, antipsychotic use in children 18 and under increased fourfold, 1998-2008, with the largest increases in those aged 7-18 years. ${ }^{25}$ In Denmark, psychotropic use in children 0-17 years increased ninefold, 1996-2010 (twofold increase when adjusting for increasing patient numbers).$^{26} \mathrm{~A}$ review of international trends in psychotropic medication use in children and adolescents found a general trend in many countries of increasing prescription rates. ${ }^{27}$ This increase in utilisation is despite only limited evidence for efficacy in these age groups, and concerns regarding potentially increased risk of suicidal ideation and self-harm. ${ }^{17}$

\section{Implications and future directions}

For those seen in the hospital, the estimated rate of repetition of non-fatal deliberate self-harm is $16 \%$ at 1 year, while a rate of suicide is $1.6 \%$ at 1 year and $3.9 \%$ at 5 years. ${ }^{28}$ A recent study of completed suicides in England in people under 20 reported that more than half had previously self-harmed. ${ }^{29}$ Thus, the patients in our study are at risk of repetition and completed suicide later in life.

The striking cohort effect observed here raises many questions about what is driving this trend. One could speculate that recent technological advancements have a role. Rising internet, social media and smartphone usage among young people could impact on mental health and responses to distress. The percentage of Australian teens who use a smartphone has increased from $23 \%$ to $80 \%$, 2011-2015 (similar percentages are seen in teenagers in the USA and UK).$^{30}$ Increasing rates of self-harm could be due to increased mental illness in this population or changing behavioural responses in this cohort. Self-harm and suicidal contagion is a well-documented phenomenon. New media (eg, prosuicide websites normalising self-harm) could facilitate this contagion. Cyberbullying and internet use, in general, has been found to correlate with self-harm, suicide and mental illness. ${ }^{31}$ Conversely, the internet may exert positive effects on young people at risk of self-harm, and there is great potential in new media for promoting positive mental health and coping strategies. ${ }^{31}$

People who self-poison often do this with medicines prescribed for them. ${ }^{14}$ Of the most common substances involved in self-poisoning listed in table 1, there is considerable overlap with leading psychotropics dispensed (tables 2 and 3), including fluoxetine, quetiapine, sertraline, escitalopram, methylphenidate, venlafaxine, fluvoxamine, risperidone, olanzapine and desvenlafaxine. Given the potential increase in suicidal ideation and behaviours in young people taking SSRIs, serotoninnorepinephrine reuptake inhibitors and ADHD medicines, ${ }^{16}$ this could be a potential contributor to increasing self-poisoning attempts. Many of these medicines (including venlafaxine, desvenlafaxine) are not recommended in children according to current guidelines, and observed increases may be a result of marketing practices. ${ }^{13}$ However, our results show some attempt to adhere to guidelines. Fluoxetine is the first-line treatment for depression in children and adolescents, and is the most prescribed antidepressant in this age group.

Given that there is little evidence for the efficacy of most psychotropics in this age group, their prescription should be carefully considered. If a psychotropic is prescribed, where possible, agents that are toxic in overdose (eg, citalopram, escitalopram, amisulpride, ${ }^{32}$ venlafaxine $^{33}$ and quetiapine ${ }^{34}$ ) should be avoided. Prescribers should be vigilant for signs of anxiety or depression in their patients and keep medicine supplies to a minimum when prescribing to patients believed to be at risk of self-harm.

Importantly, we observed high rates of poisonings with readily available over-the-counter medicines, with paracetamol and ibuprofen being the top two substances used in self-poisonings in this age group. When compared with adults (aged 20 and over), children and adolescents are more likely to use over-the-counter medicines in intentional poisonings. ${ }^{35}$ Paracetamol poisoning is the leading cause of acute liver failure in Western countries. ${ }^{36}$ In Australia, paracetamol can be in $100 \times 500 \mathrm{mg}$ $(50 \mathrm{~g})$ and $96 \times 665 \mathrm{mg}$ (modified release, $\sim 64 \mathrm{~g}$ ) packs in pharmacies and $20 \times 500 \mathrm{mg}$ packs $(10 \mathrm{~g})$ outside of pharmacies. Previous studies have demonstrated that paracetamol overdoses are often impulsive and involve the use of paracetamol present in the home. ${ }^{37}$ In 1998 , the UK restricted paracetamol pack sizes in response to increasing overdoses, liver transplants and deaths. Sales were restricted to $16 \mathrm{~g}$ within pharmacies or $8 \mathrm{~g}$ outside of pharmacies. This legislation appears effective, with a subsequent reduction in large overdoses, liver unit admissions and deaths in England and Wales. ${ }^{38-40}$ Although we did not assess outcomes of the paracetamol poisonings in our sample, similar means restriction in Australia could be implemented to reduce harm from paracetamol overdose.

The increase in self-poisoning and psychotropic use in this cohort raises three possibilities: (1) psychotropic 
prescribing predates self-poisoning and may increase suicidal ideation/self-harm tendencies; (2) psychotropic medicines are being prescribed following a self-harm attempt and (3) unrelated increase in self-poisoning and psychotropic medicines as independent markers of mental distress in this cohort. These are long-standing issues but our data demonstrate that it is increasingly important that these relationships are better characterised. Interestingly, males received the majority of antidepressant dispensings in the age group of 5-14years, and yet females in this age group were more likely to self-poison, providing some information to support point (3) above, at least in younger children. Future studies using linked data to better characterise the relationship between psychotropic prescribing and self-harm/suicide could provide valuable insights into which of these three explanations is most likely.

\section{CONCLUSION}

There has been a steep increase in self-poisonings in Australian children and adolescents, particularly since 2011. This confirms that trends seen in the UK and USA are not confined to these particular countries, possibly indicating a global phenomenon. This could foretell increases in suicide rates, and signals a generation that may require a different approach to build coping strategies and resilience.

\section{Author affiliations}

${ }^{1}$ NSW Poisons Information Centre, The Children's Hospital at Westmead, Sydney, New South Wales, Australia

${ }^{2}$ Sydney Pharmacy School, The University of Sydney, Sydney, New South Wales, Australia

${ }^{3}$ Centre for Big Data Research in Health, University of New South Wales, Sydney, New South Wales, Australia

${ }^{4}$ Victorian Poisons Information Centre and Austin Toxicology Service, Austin Health, Heidelberg, Victoria, Australia

${ }^{5}$ Victorian Poisons Information Centre, Austin Health, Heidelberg, Victoria, Australia

${ }^{6}$ Central Clinical School, The University of Sydney, Sydney, New South Wales, Australia

${ }^{7}$ Pharmacology, University of Sydney, Sydney, New South Wales, Australia

Acknowledgements We would like to thank staff at the NSW and Victorian Poisons Information Centres. We would like to thank Department of Human Services for providing data.

Contributors RC conducted the literature search, acquired NSWPIC data, analysed PIC data, interpreted data, constructed figures and wrote the draft manuscript. EAK acquired and analysed PBS data, assisted with interpretation of PBS results. AW acquired Victorian PIC data, assisted with analysis and interpretation. JAB assisted with study design, data extraction plan and interpretation of PIC results. JR acquired Victorian PIC data, assisted with analysis and interpretation. S-AP supervised data acquisition, analysis and interpretation of PBS data. AHD assisted with data analysis and interpretation. NAB supervised data analysis and interpretation, construction of figures and writing of the manuscript. All authors were involved in critical revision of the manuscript and have approved the final version.

Funding This research was supported by the National Health and Medical Research Council (NHMRC) Translational Australian Clinical Toxicology (TACT) Program, grant (ID 1055176), and the NHMRC Centre of Research Excellence in Medicines and Ageing (ID 1060407).

Competing interests $\mathrm{RC}$ is an associate investigator on an untied educational grant from Seqirus to study tapentadol misuse. This has no relation to the current study. All other authors declare no conflicts to disclose.
Patient consent for publication Not required.

Ethics approval This study was approved by The Sydney Children's Hospitals Network Human Research Ethics Committee (HREC), and the New South Wales Population and Health Services Research Ethics Committee.

Provenance and peer review Not commissioned; externally peer reviewed.

Data sharing statement PBS data are available by contacting the Department of Human Services. No further PIC data are available due to privacy concerns.

Open access This is an open access article distributed in accordance with the Creative Commons Attribution Non Commercial (CC BY-NC 4.0) license, which permits others to distribute, remix, adapt, build upon this work non-commercially, and license their derivative works on different terms, provided the original work is properly cited, appropriate credit is given, any changes made indicated, and the use is non-commercial. See: http://creativecommons.org/licenses/by-nc/4.0/.

\section{REFERENCES}

1. Hawton K, Saunders KE, O'Connor RC. Self-harm and suicide in adolescents. Lancet 2012;379:2373-82.

2. Mergl R, Koburger N, Heinrichs K, et al. What are reasons for the large gender differences in the lethality of suicidal acts? An epidemiological analysis in four european countries. PLoS One 2015;10:e0129062.

3. Finkelstein Y, Macdonald EM, Hollands S, et al. Long-term outcomes following self-poisoning in adolescents: a population-based cohort study. Lancet Psychiatry 2015;2:532-9.

4. World Health Organization. Adolescent health epidemiology [Internet]. 2017 http://www.who.int/maternal_child_adolescent/ epidemiology/adolescence/en/ (cited 5 Jul 2017).

5. Cutler GJ, Flood A, Dreyfus J, et al. Emergency department visits for self-inflicted injuries in adolescents. Pediatrics 2015;136:28-34.

6. Bottei E, Abstracts N. Increased hospitalizations and ICU admissions in poison center cases involving teenagers. Clin Toxicol 2016;54:698.

7. Tyrrell EG, Orton E, Tata LJ. Changes in poisonings among adolescents in the UK between 1992 and 2012: a population based cohort study. Inj Prev 2016;22:400-6.

8. Perera J, Wand T, Bein KJ, et al. Presentations to NSW emergency departments with self-harm, suicidal ideation, or intentional poisoning, 2010-2014. Med J Aust 2018;208:348-53.

9. Hiscock H, Neely RJ, Lei S, et al. Paediatric mental and physical health presentations to emergency departments, Victoria, 2008-15. Med J Aust 2018;208:343-8.

10. Medco. America's state of mind [Internet]. 2011:1-11 http://www. jstor.org/stable/ (cited 17 Oct 2016)

11. Wijlaars LP, Nazareth I, Petersen I. Trends in depression and antidepressant prescribing in children and adolescents: a cohort study in The Health Improvement Network (THIN). PLoS One 2012; 7:e33181.

12. Rani F, Murray ML, Byrne PJ, et al. Epidemiologic features of antipsychotic prescribing to children and adolescents in primary care in the United Kingdom. Pediatrics 2008;121:1002-9.

13. Karanges EA, Stephenson CP, McGregor IS. Longitudinal trends in the dispensing of psychotropic medications in Australia from 2009 2012: focus on children, adolescents and prescriber specialty. Aust $N$ Z J Psychiatry 2014;48:917-31.

14. Buckley NA, Whyte IM, Dawson AH, et al. A prospective cohort study of trends in self-poisoning, Newcastle, Australia, 1987-2012: plus ça change, plus c'est la même chose. Med J Aust 2015;202:438-42.

15. Hiles S, Bergen H, Hawton K, et al. General hospital-treated selfpoisoning in England and Australia: comparison of presentation rates, clinical characteristics and aftercare based on sentinel unit data. J Psychosom Res 2015;78:356-62.

16. Reith DM, Edmonds L. Assessing the role of drugs in suicidal ideation and suicidality. CNS Drugs 2007;21:463-72.

17. Cipriani A, Zhou X, Del Giovane C, et al. Comparative efficacy and tolerability of antidepressants for major depressive disorder in children and adolescents: a network meta-analysis. Lancet 2016;388:881-90.

18. Mellish L, Karanges EA, Litchfield MJ, et al. The Australian Pharmaceutical Benefits Scheme data collection: a practical guide for researchers. BMC Res Notes 2015;8:634.

19. Gunnell D, Middleton N, Whitley E, et al. Influence of cohort effects on patterns of suicide in England and Wales, 1950-1999. Br J Psychiatry 2003;182:164-70.

20. Mitchell RJ, Bambach MR, Muscatello D, et al. Can SNOMED CT as implemented in New South Wales, Australia be used for road trauma 
injury surveillance in emergency departments? Health Inf Manag 2013;42:4-8.

21. Cairns R, Brown JA, Buckley NA. The impact of codeine rescheduling on misuse: a retrospective review of calls to Australia's largest poisons centre. Addiction 2016;111:1848-53.

22. Karanges EA, Blanch B, Buckley NA, et al. Twenty-five years of prescription opioid use in Australia: a whole-of-population analysis using pharmaceutical claims. Br J Clin Pharmacol 2016;82:255-67.

23. Rheinheimer B, Kunz M, Nicolella A, et al. Trends in self-poisoning in children and adolescents in Southern Brazil between 2005 and 2013. European Psychiatry 2015;30:S136.

24. Kassebaum N, Kyu HH, Zoeckler L, et al. Child and Adolescent Health From 1990 to 2015. JAMA Pediatr 2017;171:573.

25. Alessi-Severini S, Biscontri RG, Collins DM, et al. Ten years of antipsychotic prescribing to children: a Canadian population-based study. Can J Psychiatry 2012;57:52-8.

26. Steinhausen HC, Bisgaard C. Nationwide time trends in dispensed prescriptions of psychotropic medication for children and adolescents in Denmark. Acta Psychiatr Scand 2014;129:221-31.

27. Steinhausen HC. Recent international trends in psychotropic medication prescriptions for children and adolescents. Eur Child Adolesc Psychiatry 2015;24:635-40.

28. Carroll R, Metcalfe C, Gunnell D. Hospital presenting self-harm and risk of fatal and non-fatal repetition: systematic review and metaanalysis. PLoS One 2014;9:e89944.

29. Rodway C, Tham SG, Ibrahim S, et al. Suicide in children and young people in England: a consecutive case series. Lancet Psychiatry 2016;3:751-9.

30. Australian Communications and Media Authority. Aussie teens and kids online: Research snapshot [Internet]. 2016 https://www.acma. gov.au/theACMA/engage-blogs/engage-blogs/Research-snapshots/ Aussie-teens-and-kids-online.
31. Daine K, Hawton K, Singaravelu V, et al. The power of the web: a systematic review of studies of the influence of the internet on selfharm and suicide in young people. PLoS One 2013;8:e77555.

32. Isbister GK, Page CB. Drug induced QT prolongation: the measurement and assessment of the QT interval in clinical practice. Br J Clin Pharmacol 2013;76:48-57.

33. Isbister GK. Electrocardiogram changes and arrhythmias in venlafaxine overdose. Br J Clin Pharmacol 2009;67:572-6.

34. Isbister GK, Duffull SB. Quetiapine overdose: predicting intubation, duration of ventilation, cardiac monitoring and the effect of activated charcoal. Int Clin Psychopharmacol 2009;24:174-80.

35. Huynh A, Cairns R, Brown JA, et al. Patterns of poisoning exposure at different ages: the 2015 annual report of the Australian Poisons Information Centres. Med J Aust 2018;209:74-9.

36. Larson AM, Polson J, Fontana RJ, et al. Acetaminophen-induced acute liver failure: results of a United States multicenter, prospective study. Hepatology 2005;42:1364-72.

37. Hawton K, Ware C, Mistry H, et al. Paracetamol self-poisoning. Characteristics, prevention and harm reduction. Br J Psychiatry 1996;168:43-8.

38. Hawton K, Simkin S, Deeks J, et al. UK legislation on analgesic packs: before and after study of long term effect on poisonings. BMJ 2004;329:1076-9.

39. Hawton K, Townsend E, Deeks J, et al. Effects of legislation restricting pack sizes of paracetamol and salicylate on self poisoning in the United Kingdom: before and after study. BMJ 2001;322:1203-7.

40. Bernal W. Changing patterns of causation and the use of transplantation in the United kingdom. Semin Liver Dis 2003;23:227-36. 